\title{
Effect of Iso-Thermal Treatment on the Corrosion Behaviour of Low Carbon Steel (Nigerian C2R grade) in a Buffered Solution containing Chloride and Carbonate Ions
}

\author{
Atanda P. O ${ }^{1}$, Olorunniwo O. E ${ }^{1}$, Alabi O. $D^{1}$, Oluwole. O. $\mathbf{O}^{2, *}$ \\ ${ }^{1}$ Department of Materials Science and Engineering O.A.U., Ile-Ife, Nigeria \\ ${ }^{2}$ Mechanical Engineering Department, University of Ibadan, Nigeria
}

\begin{abstract}
This work has investigated the corrosion behavior of low carbon steel subjected to four different modes of iso-thermal heat treatment and then immersed in a neutral buffer corrosive medium containing carbonate and chloride ions. The low carbon steel material was cut into twenty small pieces of length $18 \pm 2 \mathrm{~mm}$, put in groups of five and subjected to: Annealing, Hardening, Normalizing and tempering, each corresponding to an iso-thermal mode of treatment. The samples were ground and polished, and micrographs taken for each mode of treatment.The samples were then immersed into the corrosion medium; a neutral buffer and samples were withdrawn for measurement every 72 hours. The experiment lasted 360 hours (15 days). The weight loss due to corrosion of the samples, the corrosion rate of the samples and the $\mathrm{pH}$ variation of the samples were monitored against time of exposure. It was observed that samples which had undergone tempering mode of heat treatment turned out to be the ones with the best corrosion resistance.
\end{abstract}

Keywords Buffer solution, corrosion, $\mathrm{pH}$, heat-treatment, microstructures, Carbon steel

\section{Introduction}

The use of carbon steel is indispensable to virtually all aspects of human endeavor. Our human civilization cannot exist without metals and yet corrosion is their Achilles heel. Failure of parts and components of engineering origin in different industries by corrosion is one of the major problems. Corrosion is responsible for so many mishaps that have occurred in the engineering history of man. The two particular reasons for the extraordinary versatility of steel are heat treatment and alloying. These procedures alter the crystalline structure of steel, and hence it's physical properties. Steel is classed into, either mild steel $(0.10 \% \mathrm{C}-0.2 \% \mathrm{C})$, low carbon steels $(0.2 \% \mathrm{C}-0.3 \% \mathrm{C})$, medium carbon steels $(0.3 \% \mathrm{C}-0.6 \% \mathrm{C})$ and high carbon steels $(0.6 \%-1.7 \% \mathrm{C})$.

The usage of steel is well pronounced in various aspects of human life such as in manufacturing, oil and gas, construction, medical, textile, transport and aviation industries to mention a few. The steel industry as profitable and important as it is plagued by one of the most engineering-solution defying problems known to man, called Corrosion.

* Corresponding author:

lekeoluwole@gmail.com (Oluwole.O.O)

Published online at http://journal.sapub.org/ijmc

Copyright $(\underset{2}{ } 2012$ Scientific \& Academic Publishing. All Rights Reserved
Corrosion has been variously defined by many authors in recent time. According to kruger[1], corrosion is the degradation or destruction of a material that occurs when it reacts with its environment. Corrosion has also been defined as the chemical or electrochemical reaction of a metal with its environment leading in some cases to failure of the entire structure[2]. Corrosion is the destructive attack of a metal by chemical or electrochemical interactions with its environmen. Corrosion kills people, wastes resources, and costs money we can ill afford. It is presently virtually impossible to mention a single branch of the national economy of a country, particularly one highly developed technologically, where metals and metal alloys are not used as materials in the construction of plants, machines, equipments, processes, transportation, and storage facilities and sundry durable structures[4]. The form and degree of corrosion in a system depends on the composition and structure of the metal and its service envelope (That means the environment, the operation temperature, pressure and the immediate vicinity of the metal including the extent of mechanical stressing). Heat treatment is a heating and cooling operation(s) applied to metals and alloys in solid state to impact desirable properties to the metal or alloy. Heat treatment of metals is an important operation in the final fabrication process of many engineering components.

Heat treatment is of various forms which include anneal- 
ing, normalizing, tempering, hardening and isothermal operations. Heat treatment improves the microstructure of the metal, and this is what gives the metal desired properties for different service conditions. This study is therefore undertaken to establish the effect of these various heat treatment processes on the rate of corrosion of low carbon steels in different corrosion media, which in this case is a neutral buffered solution containing chloride and carbonate ions. Iso-thermal operation is a kind of treatment which depends upon the transformation that is taken place at a single predetermined temperature during a given period of time[5].

Buffer solutions are solutions that resist change in hydronium ion and the hydroxide ion concentration (and consequently $\mathrm{pH}$ ) upon addition of small amounts of acid or base, or upon dilution. Buffer solutions consist of a weak acid and its conjugate base (more common) or a weak base and its conjugate acid (less common). The resistive action is the result of the equilibrium between the weak acid (HA) and its conjugate base $\left(\mathrm{A}^{-}\right)$:

$$
\mathrm{HA}(\mathrm{aq})+\mathrm{H}_{2} \mathrm{O}(\mathrm{l}) \leftrightarrow \mathrm{H}_{3} \mathrm{O}^{+} \text {(aq) }+\mathrm{A}^{-} \text {(aq) }
$$

Any alkali added to the solution is consumed by the hydronium ions. These ions are mostly regenerated as the equilibrium moves to the right and some of the acid dissociates into hydronium ions and the conjugate base. If a strong acid is added, the conjugate base is protonated, and the $\mathrm{pH}$ is almost entirely restored. This is an example of Le Chatelier's principle and the common ion effect.

The resistance to changes in $\mathrm{pH}$ makes buffer solutions very useful for chemical manufacturing and essential for many biochemical processes. The ideal buffer for a particular $\mathrm{pH}$ has a $\mathrm{p} K_{\mathrm{a}}$ equal to the $\mathrm{pH}$ desired, since a solution of this buffer would contain equal amounts of acid and base and be in the middle of the range of buffering capacity.

Buffer solutions are necessary to keep the correct $\mathrm{pH}$ for enzymes in many organisms to work. Many enzymes work only under very precise conditions; if the $\mathrm{pH}$ strays too far out of the margin, the enzymes slow or stop working and can denature, thus permanently disabling its catalytic activity. A buffer of carbonic acid $\left(\mathrm{H}_{2} \mathrm{CO}_{3}\right)$ and bicarbonate $\left(\mathrm{HCO}_{3}{ }^{-}\right)$is present in blood plasma, to maintain a $\mathrm{pH}$ between 7.35 and 7.45 .

Industrially, buffer solutions are used in fermentation processes and in setting the correct conditions for dyes used in coloring fabrics. They are also used in chemical analysis and calibration of $\mathrm{pH}$ meters. Much work has been done on the effect of various other agricultural and local environments on low and medium carbon steels and coated low and medium carbon steels[6-11] but there is a dearth of information on the behaviour of theses steels in a buffer solution.

\section{Methodology}

\subsection{Sample Preperation}

The steel sample selected for the work was a diameter 12 $\mathrm{mm}$ hot rolled ribbed low carbon steel bar imported to Nigeria Machine Tools Ltd from Hindustan Machine Tools Ltd, India of composition given in the table 1 below, and having the mechanical properties of $403 \mathrm{~N} / \mathrm{mm}^{2}$ yield strength, 549 $\mathrm{N} / \mathrm{mm}^{2}$ ultimate tensile strength and 28.0 as percentage elongation in the as-rolled condition.

Twenty-five (25) samples of $25 \mathrm{~mm}$ long pieces of the ribbed bar were cut using hack -saw and the samples ground on one face using the pressure sensitive abrasive papers of grades 240, 320, 400 and 600 grits in succession. The dimensions of the pieces were measured using micrometre screw gauge to ascertain the cross-sectional area of the parts to be exposed to the corrosive medium.

The samples were divided into five groups; A, B, C, D and E. Group A consisting of five test samples marked as-received, group B consisting of five test samples marked 'annealed', group C consisting of five test samples marked 'normalized', group D consisting of five test samples marked 'hardened', while group E consisting of five test samples marked as 'tempered'.

\subsection{Heat Treatments}

Group B test samples were heated to austenitic temperature of $960{ }^{\circ} \mathrm{C}$ and held for one hour to ensure complete homogenization, without excessive grain growth and then cooled inside the furnace to room temperature. Group C test samples were heated to austenitic temperature of $960^{\circ} \mathrm{C}$ and held for one hour to ensure complete homogenization, without excessive grain growth and then taken out of the furnace for air-cooling to room temperature. Group D test samples were also heated to austenitic temperature of $960^{\circ} \mathrm{C}$ and held for one hour to ensure complete homogenization, without excessive grain growth and then quenched in cold water to room temperature. Group E samples were heated to $700^{\circ} \mathrm{C}$, held for one hour and then quench in water. The samples were again re-heated at $550^{\circ} \mathrm{C}$ in the furnace for half an hour and air-cooled to room temperature.

\subsection{Preparation of Corrosive Environment}

The corrosion medium is a neutral buffer solution containing chloride and carbonate ions. This was prepared by using carbonic acid $\left(\mathrm{H}_{2} \mathrm{CO}_{3}\right)$ and Sodium Chloride $(\mathrm{NaCl})$. The Carbonic acid was obtained from uncontaminated rain water which is a natural neutral buffer. It was tested to ascertain its buffering capacity and a $\mathrm{pH}$ of 6.89 .

Table 1. Chemical composition of low carbon steel used for the experimentation

\begin{tabular}{|c|c|c|c|c|c|c|c|c|c|}
\hline ELEMENT & $\mathrm{C}$ & $\mathrm{Si}$ & $\mathrm{Mn}$ & $\mathrm{Ni}$ & $\mathrm{Cr}$ & $\mathrm{Mo}$ & $\mathrm{Cu}$ & $\mathrm{S}$ & $\mathrm{P}$ \\
\hline$\%$ COMPOSITION & 0.23 & 0.21 & 0.60 & 0.10 & 0.11 & 0.14 & 0.28 & 0.06 & 0.04 \\
\hline
\end{tabular}


Varying proportions of nacl was added to one litre of rain water in multiples of one gram. After adding 6 grams, the $\mathrm{pH}$ began to stabilize at 7.01. Three additional grams of $\mathrm{NaCl}$ was added with $\mathrm{pH}$ change and the solution was divided into two $50 \mathrm{~cm}^{3}$ volume each. The objective was to determine the metal which is the most corrosion resistant of all the metal samples of the low carbon steel, based on the mode of heat-treatment to which each sample was subjected. Two containers each contained one group of a treatment mode and another was set aside without any metal immersed as a control medium. Using the $\mathrm{pH}$ meter, the $\mathrm{pH}$ of the corrosive medium was measured and recorded after every 7 days (this also included the control corrosive). As a precautionary measure, the measurement of the $\mathrm{pH}$ involved the standardization of the $\mathrm{pH}$ meter. This was done by dipping the meter into distilled water which has a $\mathrm{pH}$ of 7.0 after which the rod was thoroughly cleaned with tissue paper and then immersed into different corrosive media.

\subsection{Weight Loss Measurement and Microstructural Examination}

All the samples were prepared according to the normal metallographic procedure of grinding, polishing and etching, after which structures were examined and micrographs taken. The samples were all appropriately labelled and weighed using a chemical balance.

After every 7 days (one week), the samples were swabbed with ethanol, dried, weighed and examined for variations of corrosion products and pits and then observed under a metallurgical microscope for more detailed information. The experiment lasted for 15 days.

\section{Results and Discussion}

The results of the $\mathrm{pH}$ variation with time of exposure to the corrosive medium for each category heat-treated samples and the control solution are as follows in Figure 1. Similarly, Figures 2 and 3 show the weight loss and corrosion penetration rate respectively for each category heat-treated samples with exposure time in the corrodent. Figure 4 shows the micrograph of the as-received carbon steel. Figures 5-8 show micrographs of progressive surface corrosion on annealed, hardened, normalized and tempered low carbon steel during the test period.

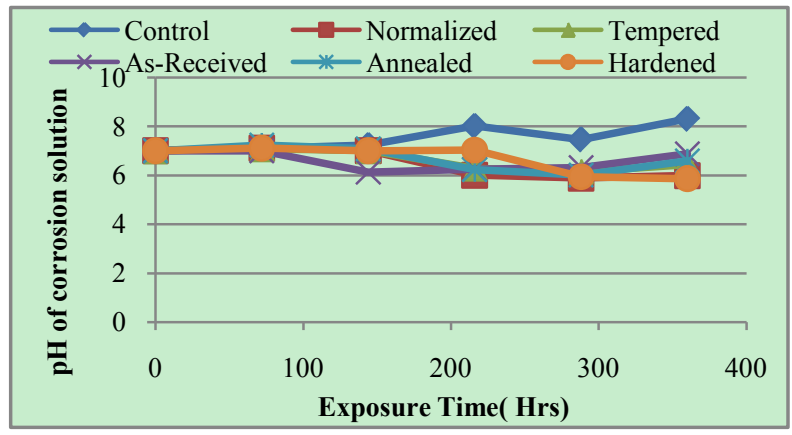

Figure 1. $\mathrm{pH}$ of corrosion solution

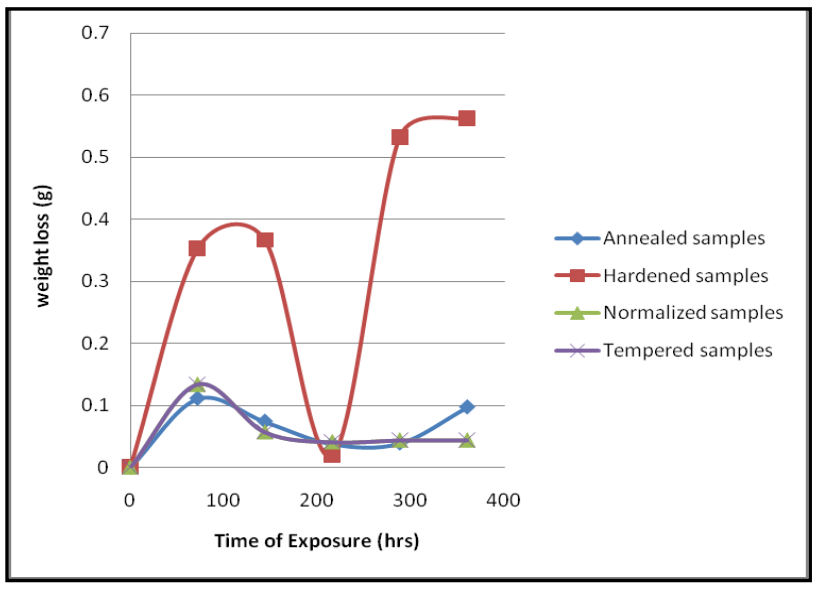

Figure 2. Weight loss against Time of Exposure

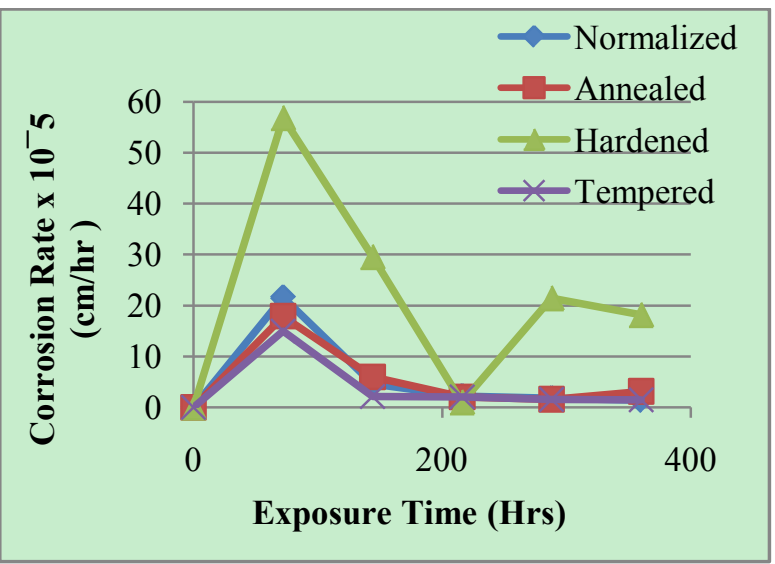

Figure 3. Corrosion Penetration Rate against Time of Exposure

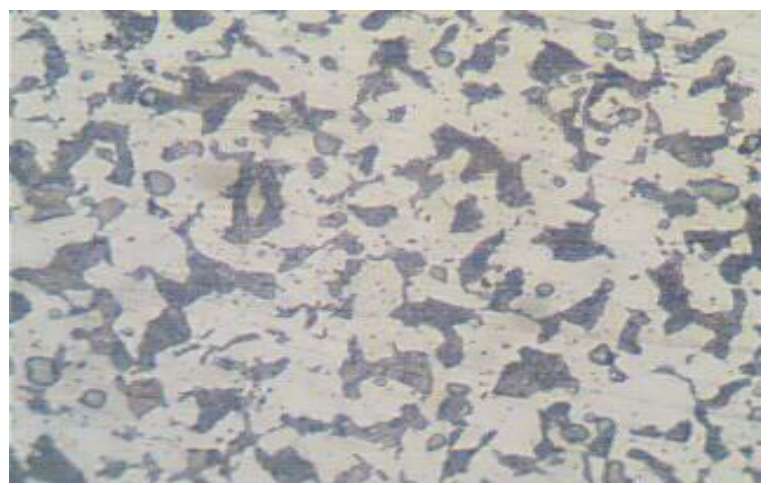

Figure 4. As-Received Sample

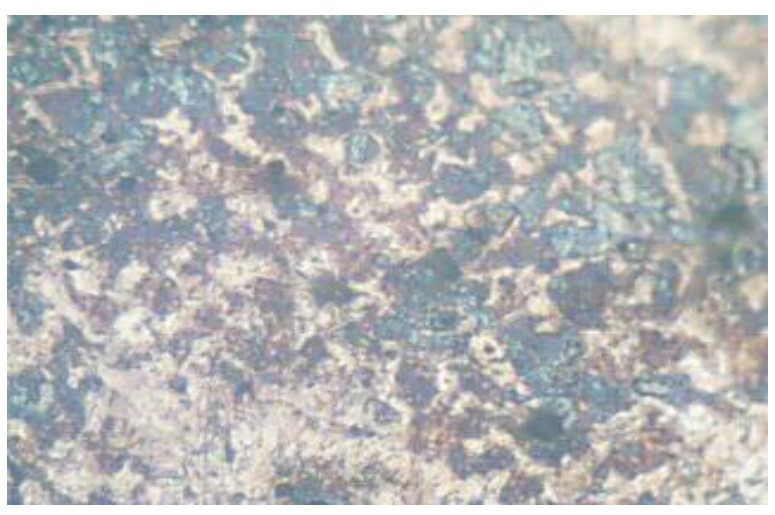

a 


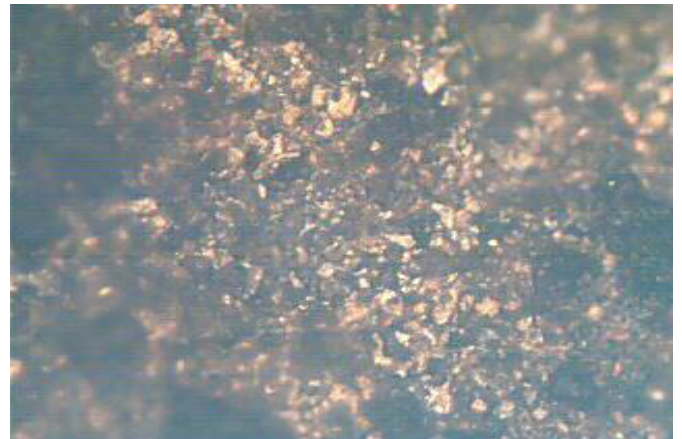

b

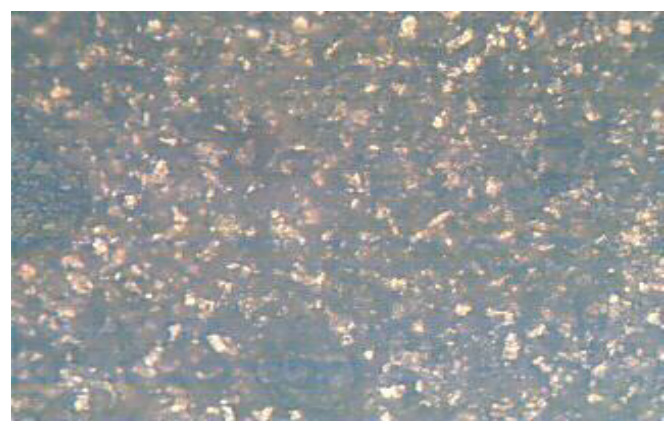

c

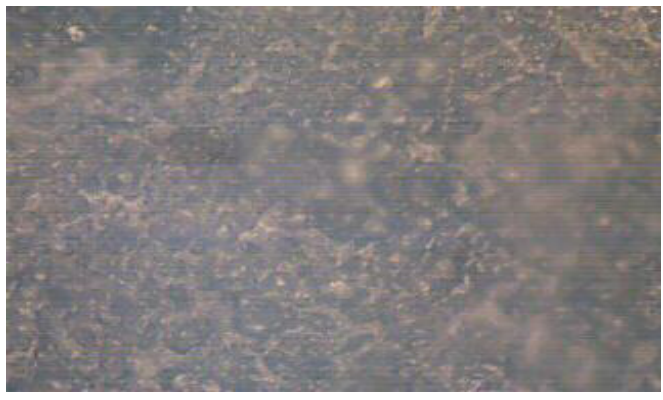

d

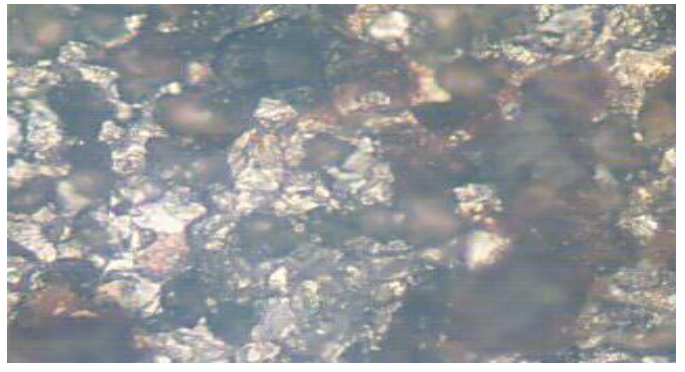

e

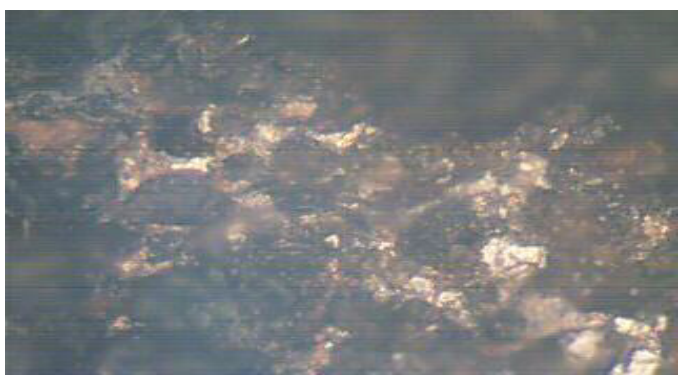

f

Figure 5. a: Annealed Sample, un-corroded. b: Annealed Sample 3 days in corrosion fluid. c: Annealed Sample 6 days in corrosion fluid. d: Annealed Sample 9 days in corrosion fluid. e: Annealed Sample 12 days in corrosion fluid. f: Annealed Sample 15 days in corrosion fluid

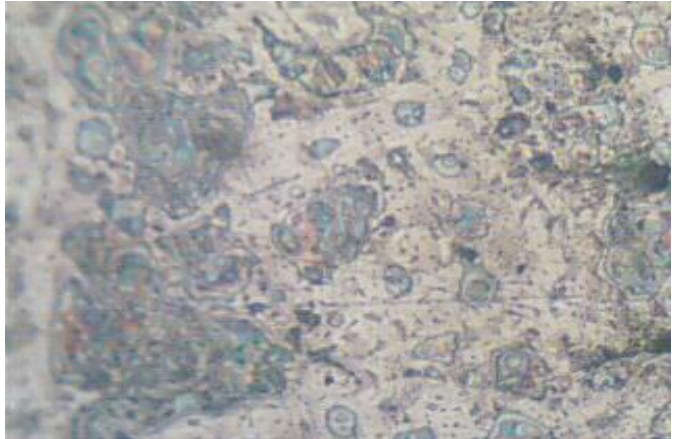

a
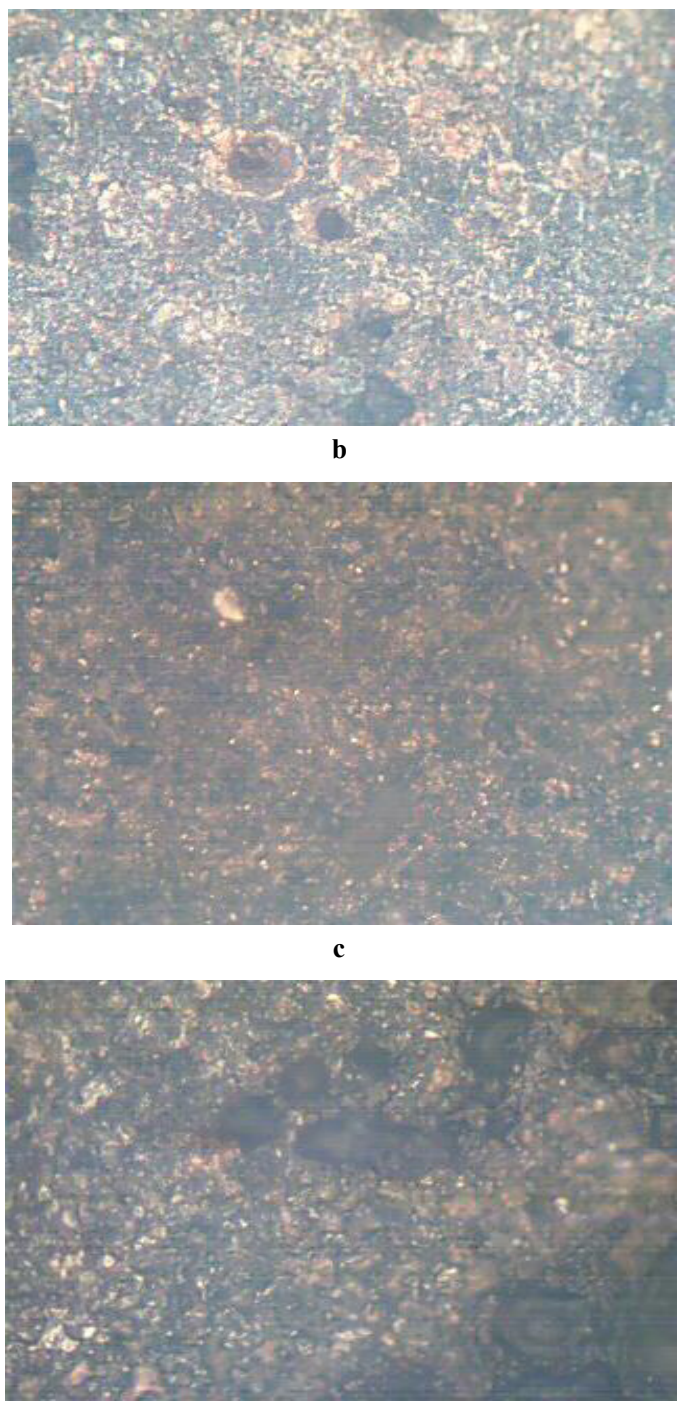

d

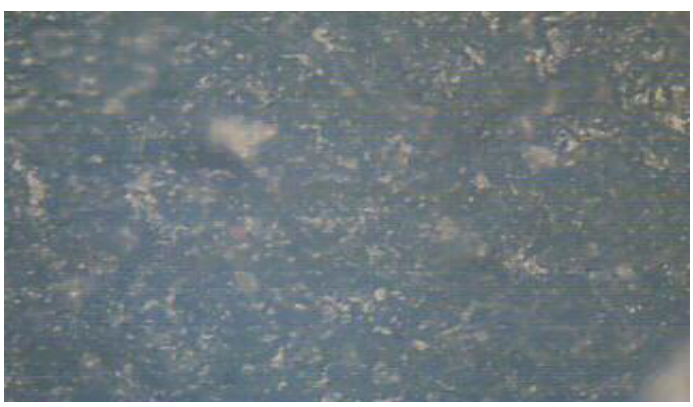




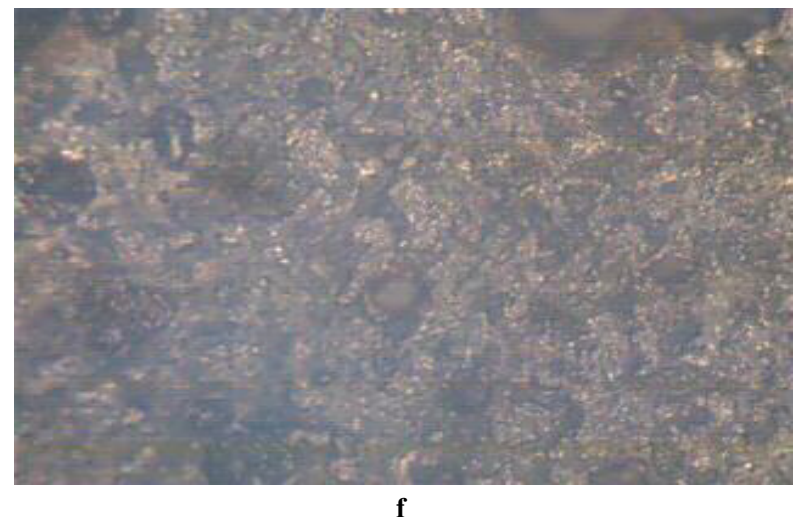

Figure 6. a:non-corroded hardened Sample. Hardened Sample 3 days in corrosion fluid. $\mathrm{c}$ : Hardened Sample 6 days in corrosion fluid. $\mathrm{d}$ : Hardened Sample 9 days in corrosion fluid. e : Hardened Sample 12 days in corrosion fluid. $\mathrm{f}$ : Hardened Sample 15 days in corrosion fluid

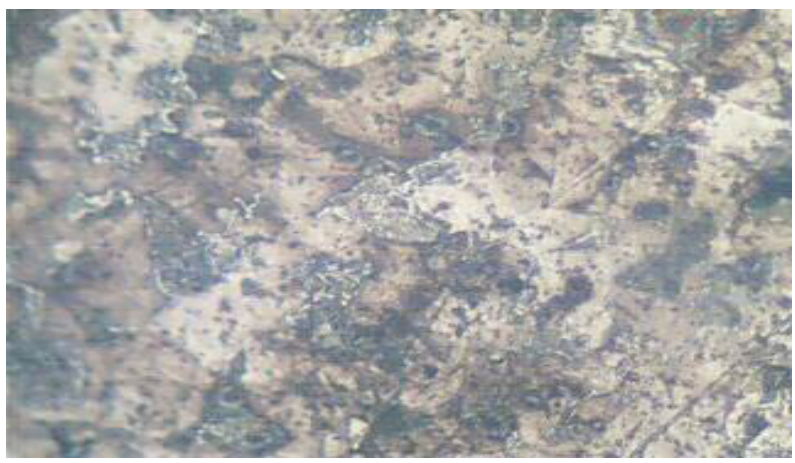

a

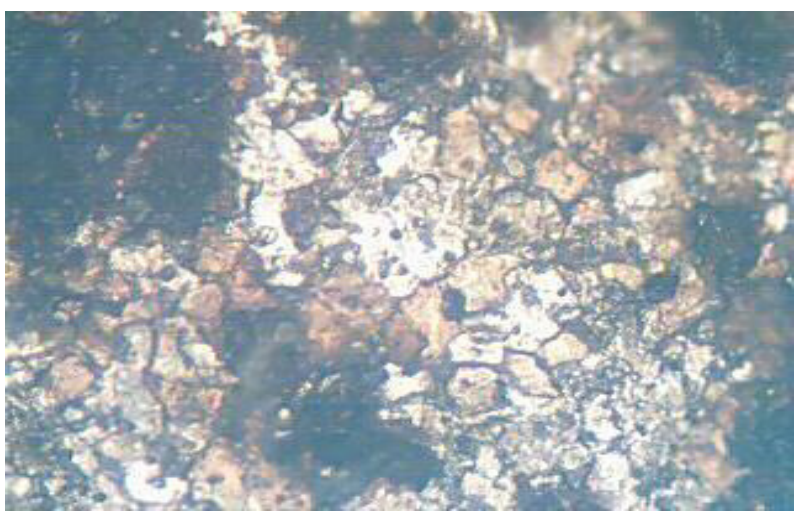

b

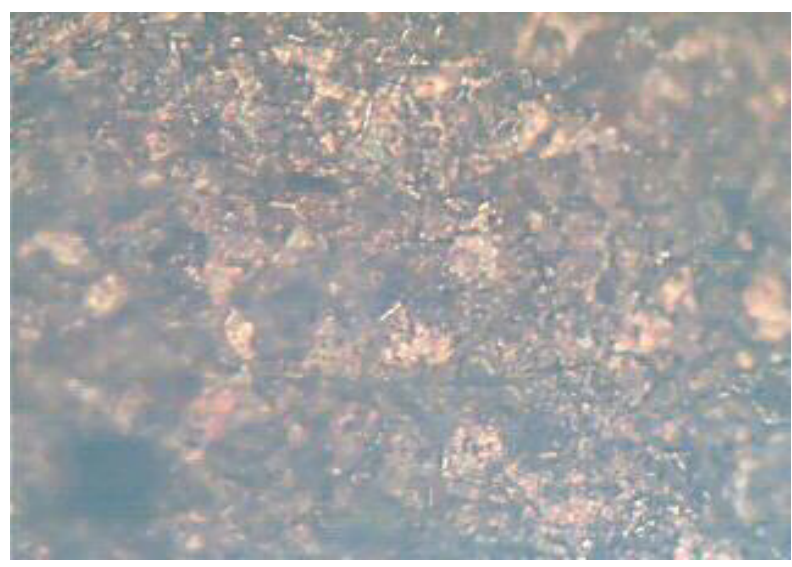

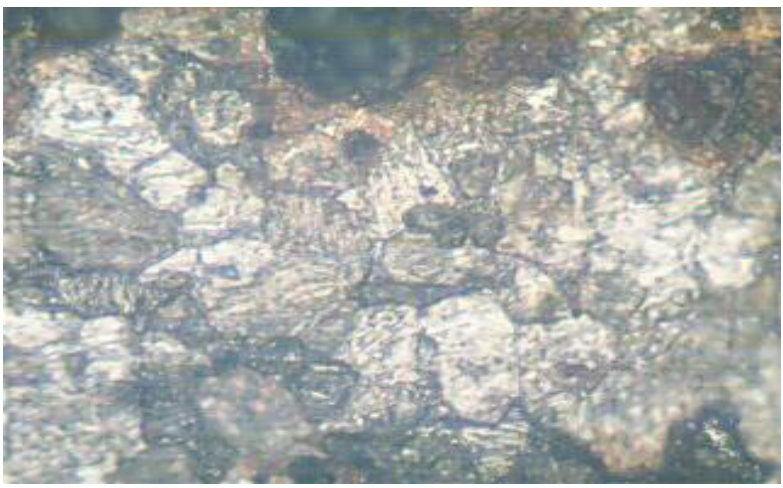

\section{d}

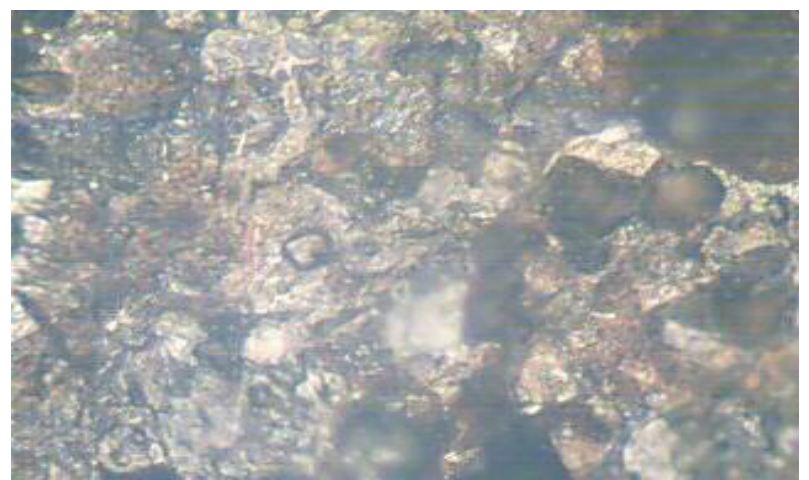

e

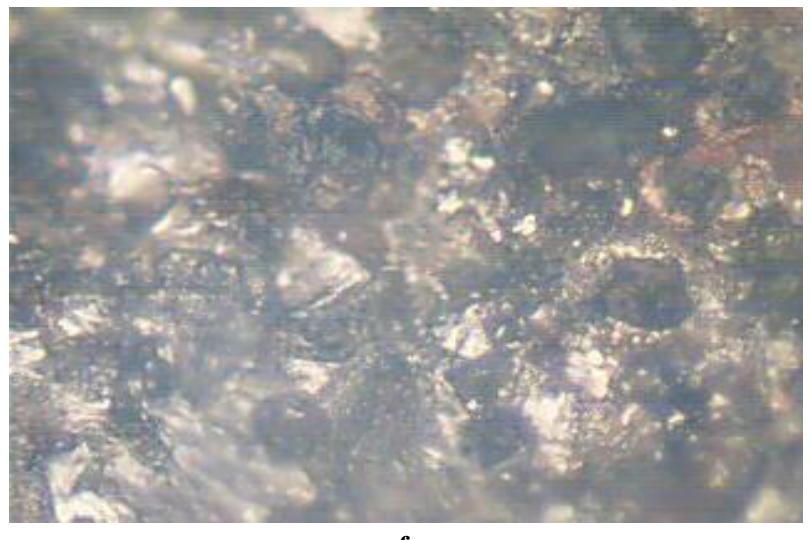

f

Figure 7. a: Normalized Sample before corrosion. b: Normalized Sample 3 days in corrosion fluid. c: Normalized Sample 6 days in corrosion fluid. d: Normalized Sample 9 days in corrosion fluid. e: Normalized Sample 12 days in corrosion fluid. f: Normalized Sample 15 days in corrosion fluid

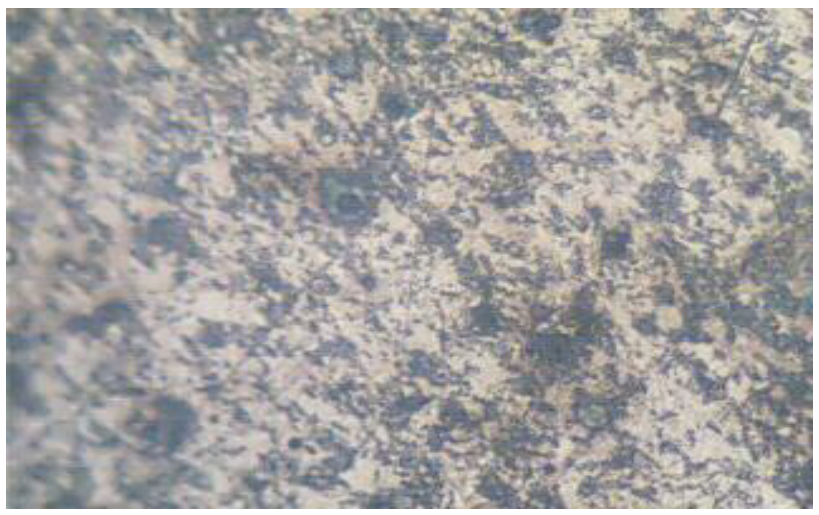

a 


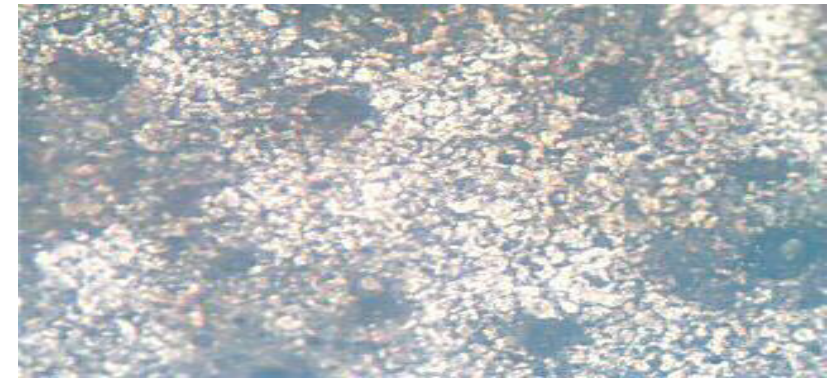

b

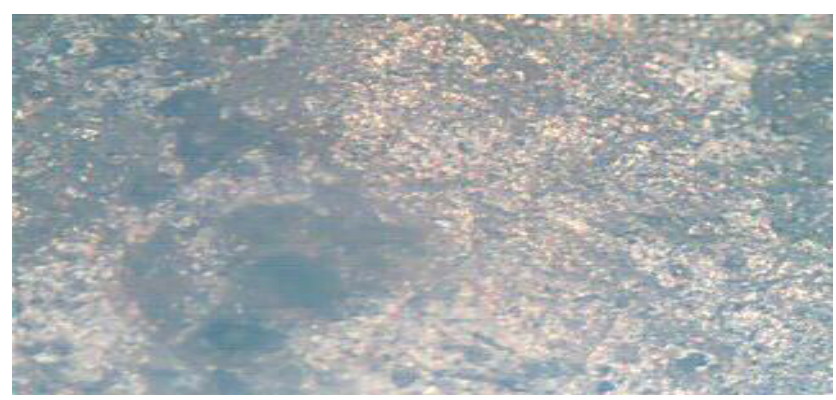

c

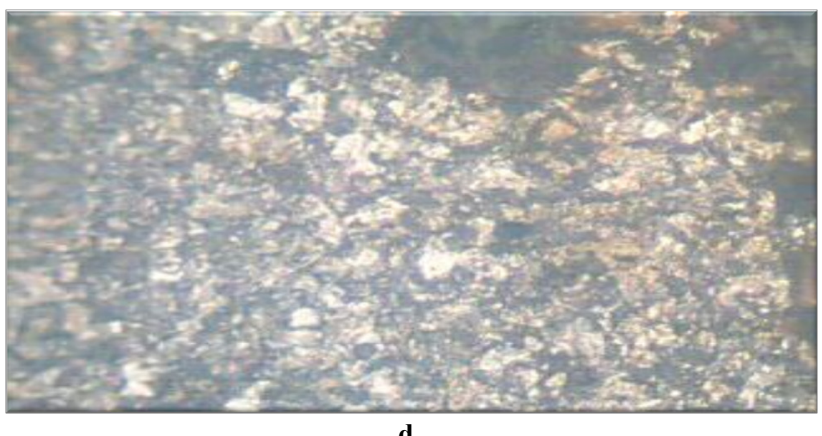

d

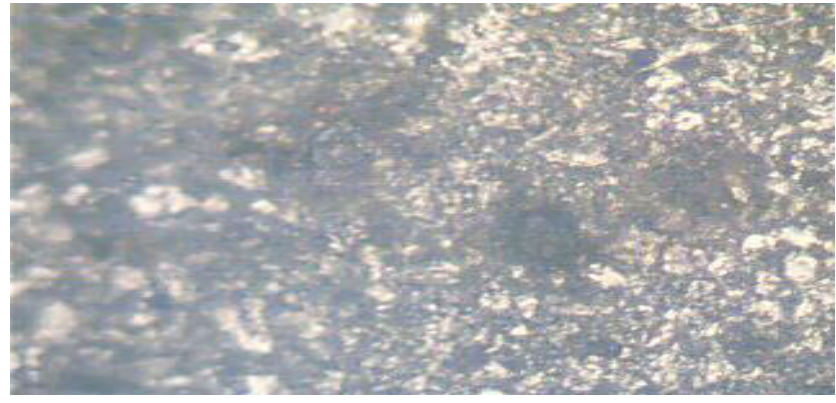

e

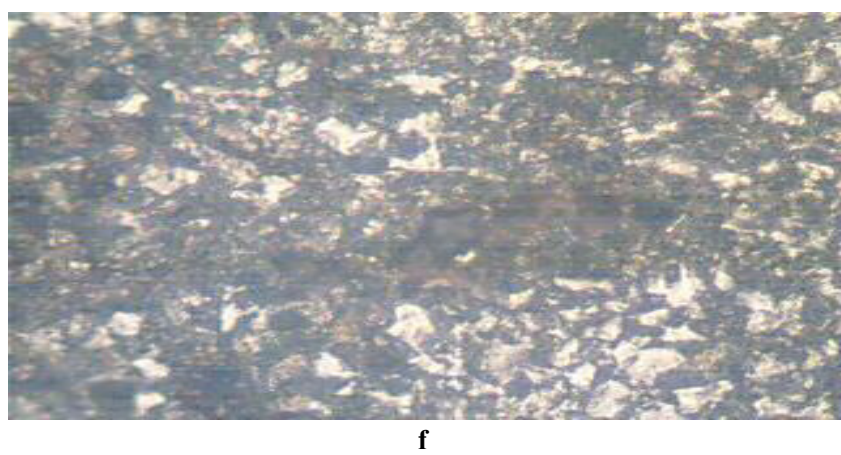

Figure 8. a: Tempered Sample before corrosion. b: Tempered Sample 3 days in corrosion fluid. c: Tempered Sample 6 days in corrosion fluid. d: Tempered Sample 9 days in corrosion fluid. 8e: Tempered Sample 12 days in corrosion fluid. f: Tempered Sample 15 days in corrosion fluid

\section{pH Variation}

The $\mathrm{pH}$ of the buffer solution containing the various metallographic samples is shown in Figure 1. Generally the $\mathrm{pH}$ of the system went slightly acidic in all the mediums. This increase could be attributed to the presence of corrosion products.

\section{Corrosion Behavior of Annealed Sample}

The annealed structure (figure 5a) consists of dark pearlite phases in a ferrite matrix. An initial corrosion rate of $17.58 \times 10^{-5} \mathrm{~cm} / \mathrm{hr}$ was observed after 72 hours. This corrosion rate could be attributed to the larger portion of pearlite formed from cooling austenite.

After 72 hours of soaking, a thick film of corrosion products was observed to cover the material surface (figure $5 b-e)$. This is due to the depletion of both pro-eutectoid ferrite and pearlite in the structure.

A drop in the corrosion rate was observed( Fig.3), between the $144^{\text {th }}$ hour and the $216^{\text {th }}$ hour. The corrosion rate decreased due to the thicker corrosion products covering the surface of the sample, thus it formed a kind of protective film on the surface which retarded the corrosion rate towards the end of the experiment.

\section{Corrosion Behavior of the Hardened Sample}

This sample had the most pronounced behavior of all the different modes of heat treatment. This sample showed the greatest weight loss trends of all the heat treatment modes( Fig.2).

The initial corrosion rate notice at $72^{\text {nd }}$ hour was the highest after which it took a dive from the $72^{\text {nd }}$ to the $216^{\text {th }}$ hour( Fig.3). This initial rise in corrosion rate could be because of the residual stresses in the steel which may have arisen due to rapid cooling. The structure revealed very little evidence of needle like features, and this is due to the low carbon content in the steel. Due to the low carbon, rapid cooling or quenching resulted in one or more structures intermediate between austenite and pearlite( Fig.6a). The corrosive product film on the metal sample became thicker from the $144^{\text {th }}$ hour, showing reduced corrosion rates( Fig.6c-f).

From the $216^{\text {th }}$ to the $288^{\text {th }}$ hour a rise in the corrosion rate was noticed and then as it approached 360 hours of exposure, it began to drop.

This sample so far revealed the poorest corrosion resistance. From a thermodynamic point of view the high energy state of the hardened/quenched sample is unstable and will want revert naturally to a lower energy state. Hence, the rapid corrosion with evidence of pitting (figure 6)

\section{Corrosion behavior of the normalized sample}

The normalized structure of the sample is composed of small quantities of pearlite phases in a ferrite matrix (figure 7a).

The normalized sample also followed the trend of initial rapid corrosion within the first 72 hours and a gradual drop approaching $216^{\text {th }}$ hour( Fig.3).

Very dark portions are noticed at 72 hours of sure( Fig.7b), due to rapid corrosion and this spreads gradually to the entire surface of the sample gradually with the 
film becoming thicker (figures 7c-f)).

\section{Corrosion Behavior of the Tempered Sample}

The structure of the tempered sample is composed of carbide nodules in a ferrite matrix( Fig.8a). The tempered sample before soaking revealed uniform distribution of the pearlite phase more stable at room temperature. This is due to fact that, the higher the tempering temperature the more closely will the structure revert to a pearlite one[5].

Between the $72^{\text {nd }}$ and the $360^{\text {th }}$ hour i.e. the first and final days, corrosion rate was significant between the $72^{\text {nd }}$ and $144^{\text {th }}$ hour and only slightly at the $216^{\text {th }}$ hour as can be seen in Fig. 3 the bottom crawling nature of the tempered line on the graph.

This sample showed the best resistance to corrosion of all the different modes of heat treatment employed, with less production of corrosion products characterized by a relatively clear sample surface even at 360 hours of exposure(Figs.8b-f). This could be due to the low stress levels in the steel sample which makes the localized breakdown of the passivity more difficult than in any other structure[4]. Thus, the sample had low corrosion rates with very mild pitting on the surface.

\section{Conclusions}

From the foregoing, it can be concluded that the heat treatment mode best suited for corrosive environments with identical characteristics as that of the neutral buffer solution (such as natural waters e.g. borehole water and some

compositions of brackish waters in heavy rainfall regions) containing carbonate and chloride ion is tempering heat treatment as it impacts good corrosion resistance and low loss of weight on the metal.

Also based on results of this work, it could be concluded that the hardening sample gave the poorest resistance to corrosion with the most significant weight losses, and should be avoided in practice.

\section{REFERENCES}

[1] Kruger, J. (1986), Corrosion of metal: An overview in M.B Bever (ed),ency. of materials science and engineering vol 2
[2] Nwoko, V.O. (1976), Corrosion of municipal water pipes, The Nigeria Engr. Vol 26

[3] Uhlig, H.H., 1971 "Corrosion and corrosion control: An introduction to Corrosion Science and Engineering" John Wiley and Sons Inc., New York. 1971. Pp 37-80,229-245.

[4] J.A., 1994 'On the effects of some heat treatments on the corrosion and corrosion-wear of ST $60 \mathrm{Mn}$ steel in bitumen hot-water extraction from tar sand environments'. Unpublished B.Sc. Thesis, Department of Metallurgical and Materials Engineering, Obafemi Awolowo University, ile-ife, Osun state.

[5] T.V., Sharma C.P. and Sharma A. (1988), Heat treatment principles and techniques, prentice hall of India private limited, New Delhi, Pp. 323-335.

[6] Oluwole.O.O, Oloruntoba. D.T, And Awheme. O (2008) "Effect of zinc plating of low carbon steel on corrosion resistance in cassava fluid environment" Corrosion Engineering Science andTechnology, Institute of Materials, Minerals and Mining, UK.. 43(4),320-323.

[7] Oloruntoba. D.T, Oluwole.O.O And Oguntade. E.O (2009) 'Comparative Study of corrosion behaviour of galvanized Steel and coated Al roofing sheet in Chloride and Carbonate environments' J. Materials. \& Design, Elsevier, UK 30(4), 1371-1376.

[8] Oluwadare.G.O, Akindahunsi, A.A, Oluwole. O.O And Agbaje.I.A (2009) "Effect of Cassava Juice on Corrosion of Mild and High Yield Steel Bars in Concrete Structures" Nigerian Society of Engineers Technical Transactions44(1), 46-56.

[9] Oluwole, O.O And Olorunfemi, O (2009) 'Corrosion Behaviour Of Nickel Plated Medium Carbon Steel In Cocoa Liquor' Pacific Journal Of Science And Technology, Akamai University, USA 10(2),172-177

[10] Oluwole.Oo, Atanda.A.A, Odekunbi .O.A and Adegbaju. E(2009) 'Corrosion Behaviour Of 18/8 Stainless Steel And Nickel-Plated Low Carbon Steel In Cassava Fluid' Journal of minerals and materials characterization and Engineering, Michigan Technological University, USA.8(10),803-811

[11] Oluwole, O.O And Olawale, O (2010) 'Corrosion Behaviour Of Nickel Plated Low Carbon Steel In Tomato Fluid' Leonardo Electronic Journal of Practices and Technology,Technical University of Cluj-Napoca, Romania. 9(16),33-42 